\title{
Post-buckled precompressed elements: a new class of control actuators for morphing wing UAVs
}

\author{
Roelof Vos ${ }^{1}$, Ron Barrett ${ }^{1}$, Roeland de Breuker ${ }^{2}$ and Paolo Tiso ${ }^{2}$ \\ ${ }^{1}$ University of Kansas, Department of Aerospace Engineering, 2120 Learned Hall, \\ 1530 W 15th St., Lawrence, KS 66045, USA \\ ${ }^{2}$ Delft University of Technology, Faculty of Aerospace Engineering, Kluyverweg 1, 2629 HS, \\ Delft, The Netherlands \\ E-mail: roelof_vos@hotmail.com
}

Received 24 September 2006, in final form 13 March 2007

Published 18 May 2007

Online at stacks.iop.org/SMS/16/919

\begin{abstract}
This paper describes how post-buckled precompressed (PBP) piezoelectric bender actuators are employed in a deformable wing structure to manipulate its camber distribution and thereby induce roll control on a subscale UAV. By applying axial compression to piezoelectric bimorph bender actuators, significantly higher deflections can be achieved than for conventional piezoelectric bender actuators. Classical laminated plate theory is shown to capture the behavior of the unloaded elements. A Newtonian deflection model employing nonlinear structural relations is demonstrated to predict the behavior of the PBP elements accurately. A proof of concept $100 \mathrm{~mm}\left(3.94^{\prime \prime}\right)$ span wing employing two outboard PBP actuator sets and a highly compliant latex skin was fabricated. Bench tests showed that, with a wing chord of $145 \mathrm{~mm}\left(5.8^{\prime \prime}\right)$ and an axial compression of $70.7 \mathrm{gmf} \mathrm{mm}^{-1}$, deflection levels increased by more than a factor of 2 to $15.25^{\circ}$ peak-to-peak, with a corner frequency of $34 \mathrm{~Hz}$ (an order of magnitude higher than conventional subscale servoactuators). A $1.4 \mathrm{~m}$ span subscale UAV was equipped with two PBP morphing panels at the outboard stations, each measuring $230 \mathrm{~mm}$ $\left(9.1^{\prime \prime}\right)$ in span. Flight testing was carried out, showing a $38 \%$ increase in roll control authority and 3.7 times greater control derivatives compared to conventional ailerons. The solid state PBP actuator in the morphing wing reduced the part count from 56 down to only 6 , with respect to a conventional servoactuated aileron wing. Furthermore, power was reduced from $24 \mathrm{~W}$ to $100 \mathrm{~mW}$, current draw was cut from 5 A to $1.4 \mathrm{~mA}$, and the actuator weight increment dropped dramatically from $59 \mathrm{~g}$ down to $3 \mathrm{~g}$.
\end{abstract}

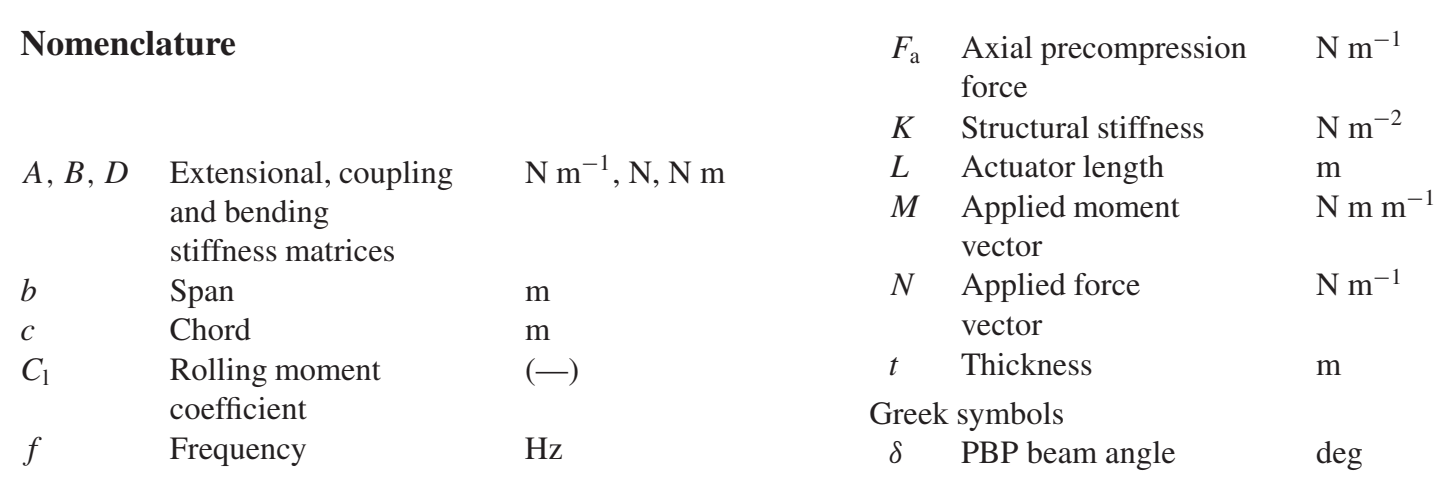




\begin{tabular}{|c|c|c|}
\hline$\delta_{0}$ & $\begin{array}{l}\text { Trailing-edge } \\
\text { deflection }\end{array}$ & deg \\
\hline$\epsilon$ & Normal strain & - \\
\hline$\kappa$ & Curvature & $\operatorname{deg} \mathrm{m}^{-1}$ \\
\hline$\Lambda$ & Virgin actuator strain & - \\
\hline$\sigma$ & Normal stress & $\mathrm{N} \mathrm{m}^{-2}$ \\
\hline$\omega_{n}$ & Natural frequency & $\mathrm{s}^{-1}$ \\
\hline$\theta$ & End rotation & deg \\
\hline$\Theta$ & $\begin{array}{l}\text { Normalized end } \\
\text { rotation }\end{array}$ & - \\
\hline$\varphi$ & Deviation angle & $\operatorname{deg}$ \\
\hline \multicolumn{3}{|c|}{ Subscripts } \\
\hline $\mathrm{a}$ & Actuator & \\
\hline $\mathrm{b}$ & Bonding layer & \\
\hline ex & External & \\
\hline 1 & Laminate, lower skin & \\
\hline $\mathrm{sp}$ & Spring & \\
\hline $\mathrm{t}$ & Thermal & \\
\hline te & Trailing edge & \\
\hline $\mathrm{u}$ & Upper skin & \\
\hline \multicolumn{3}{|c|}{ Abbreviations } \\
\hline CLPT & $\begin{array}{l}\text { Classical laminated } \\
\text { plate theory }\end{array}$ & \\
\hline LNPS & $\begin{array}{l}\text { Low net passive } \\
\text { stiffness }\end{array}$ & \\
\hline PBP & Post-buckled precompressed & \\
\hline PZT & Lead Titanate Zirconate & \\
\hline UAV & $\begin{array}{l}\text { Uninhabited aerial } \\
\text { vehicle }\end{array}$ & \\
\hline ZNPS & $\begin{array}{l}\text { Zero net passive } \\
\text { stiffness }\end{array}$ & \\
\hline
\end{tabular}

\section{Introduction}

For more than ten years adaptive structures have been used to improve flight control on uninhabited aircraft. These research projects have led to practical, flightworthy, and ultimately, fielded active wings, solid state flap mechanisms and solid state rotors. These designs were all demonstrated in bench tests, wind tunnel tests and eventually in flight [1-7]. In 1996 a rotary wing UAV showed that flight control weight could be cut by $40 \%$ while decreasing both power consumption and drag simultaneously [8, 9]. In 2000 it was shown that by using shape-memory-alloy filaments the pitch of the individual wings could be altered, thereby generating large control forces [10]. An important disadvantage however, was the increase in power consumption by a factor of two compared to conventional electromechanical actuators.

Instead of employing rigid lifting surface deflections or wing pitch control, it is possible to use compliant materials to deform a wing structure. In the past, different approaches were taken to induce structural deformations of wing structures: active wing twist, leading edge deformation or camber variations [11]. Each of these approaches was shown to work quite well for membrane wing UAVs; conventional wing structures employing ribs and spars often result in much higher net passive stiffnesses in all modes. To manipulate deformation in such a wing for flight control, the inherent stiffness of the structure has to be overcome while the airloads must be accommodated. To this extent, a compliant structure can be designed which minimizes the amount of energy invested in straining the passive structure.

Accordingly, adaptive structures with integrated actuators in net compliant structures are ideally suited to the task. To avoid large power consumption, piezoelectric materials are typically more advantageous than many other classes of adaptive materials especially including shape-memory alloys. However, traditional actuator schemes for piezoelectric actuators tend to trade force at the expense of deflection or deflection at the expense of force, generally leading to a loss in work, an increase in complexity and a weight penalty.

To avoid these disadvantages, a new class of piezoelectric elements called post-buckled precompressed (PBP) actuators were conceived, which increased both deflection and force simultaneously [12-14]. The force produced by a conventional piezoelectric actuator can be expressed as: $F_{\text {piezo }}=K \Delta x$, where $F_{\text {piezo }}$ fights against a comparably high stiffness of the structure, $K$, resulting in a relatively small $\Delta x$. The PBP actuator, on the other hand, relies on a low net passive stiffness (LNPS) or even a zero net passive stiffness (ZNPS) of the structure and works on a fundamentally different principle: $F_{\text {piezo }}=\left(K-K_{\mathrm{sp}}\right) \Delta x$, where $K_{\mathrm{sp}}$ is a negative spring rate mechanism and approaches $K$, thereby increasing deflections for a given force level [15-20].

The PBP principle was first demonstrated in the late 1990s by applying an axial compression force close to the buckling load of a piezoelectric (PZT) bender actuator, thereby reducing the net passive stiffness of the structure. It was shown that the energy conversion efficiency was higher for the PBP element than the conversion efficiency of the raw piezoelectric material itself. While most PZT elements are only $30-80 \%$ efficient, it was demonstrated that it is possible to get close to $100 \%$ efficiency $[21,22]$. Although originally these enhanced-performance actuators were employed as electrical transformer mechanisms ([21]), it was shown that subscale UAVs could greatly benefit from their advantages over conventional actuators. Extensive tests showed that a compressive force close to the buckling load of the PZT elements could increase free deflections up to a factor of four $[13,14]$.

Structural modeling of PPB elements has been successfully done analytically, semi-analytically and by finite element analysis. Although finite element methods are widely used [23, 24], they can become computationally expensive and might prove challenging if used in combination with optimization routines and sensitivity analyses. Semi-analytic models based on a Rayleigh-Ritz approach were shown to be beneficial when relatively complicated boundary conditions applied [25]. Closed form solutions were conceived for compressed beams in simply supported configurations [13, 14]. These solutions are now expanded to cantilevered beams that experience more complex boundary conditions.

This paper presents this new class of flight control actuators as integrated into a flexible wing, allowing it to be deformed ('morph') upon actuation. By using PBP actuators the aim was to reduce weight, complexity and power consumption with respect to conventional actuators, while increasing control bandwidth and control authority. 
PBP elements for morphing wing UAVs

\section{Actuator arrangement and analytical modeling}

To model the behavior of a free (not axially compressed) piezoelectric bender element classical laminated plate theory (CLPT) has proven successful $[2,6]$. The laminate of the bimorph PZT bender element consists of an aluminum substrate $(t=0.0768 \mathrm{~mm})$ with two symmetric PZT 5A sheets $(t=0.191 \mathrm{~mm})$ attached at either side (bonding layer thicknesses of $0.031 \mathrm{~mm}$ ). The mismatch in coefficient of thermal expansion between the PZT and the aluminum substrate induces in-plane compression in the tension-sensitive piezoceramic elements when cured at elevated temperatures and brought back to operational temperature. The resultant forces and moments in the laminate are obtained by integrating the stress over the thickness of the laminate (equation 4.14 in [26]):

$$
N=\int \sigma \mathrm{d} z \quad M=\int \sigma z \mathrm{~d} z
$$

The forces and moments in equation (1) can be subcategorized as actuator in-plane forces and moments (a), external forces and moments (ex) and forces and moments due to a mismatch in coefficients of thermal expansion $(t)$. These factors induce in-plane laminate strains, $\epsilon$, and out-of-plane curvatures, $\kappa[13]$ :

$$
\left(\begin{array}{l}
N \\
M
\end{array}\right)_{\mathrm{a}}+\left(\begin{array}{l}
N \\
M
\end{array}\right)_{\mathrm{ex}}+\left(\begin{array}{l}
N \\
M
\end{array}\right)_{\mathrm{t}}=\left[\begin{array}{ll}
A & B \\
B & D
\end{array}\right]_{1}\left(\begin{array}{c}
\epsilon \\
\kappa
\end{array}\right)_{1} .
$$

Because the curvature of the laminate is investigated, thermally induced strains can be omitted because they are balanced about the through-thickness axis of symmetry. By ignoring external forces and moments (the element is free to move) equation (2) reduces to:

$$
\left[\begin{array}{ll}
A & B \\
B & D
\end{array}\right]_{\mathrm{a}}\left(\begin{array}{c}
\Lambda \\
0
\end{array}\right)_{\mathrm{a}}=\left[\begin{array}{ll}
A & B \\
B & D
\end{array}\right]_{1}\left(\begin{array}{c}
\epsilon \\
\kappa
\end{array}\right)_{1} .
$$

Remembering that $\Lambda$ represents the strain in the piezoelectric elements, equation (3) shows how the in-plane strain $(\epsilon)$ and the curvature $(\kappa)$ of the laminate (1) are related to the free strain of the actuator (a). Since this laminate is symmetric in both material and geometrical properties with respect to the midplane of the laminate, the coupling stiffness, $B_{1}$, become zero (section 4.3.2 in [26]. Applying this to equation (3) the curvature of the laminate can be directly coupled to the strain, $\Lambda$, in the actuators (equation 4 in [13]):

$$
\kappa=\frac{B_{\mathrm{a}}}{D_{1}} \Lambda .
$$

In the PBP configuration, bending imperfections in the laminate that are introduced by the piezoelectric strain, $\Lambda$, are effectively magnified by an axial force. The PBP actuator that was used in the morphing wing configuration can be modeled as a cantilevered Euler beam which is axially compressed by a force, $F_{\mathrm{a}}$. The force is applied at the tip of the actuator and acts at an angle $\varphi$ with respect to the $x$ axis. Figure 1 shows a schematic representation of the axially compressed PBP element.

In figure 1 , it is assumed that the element is only loaded in pure bending and, to comply with the assumption that an Euler beam is inextensible, the rotations are assumed to be moderate

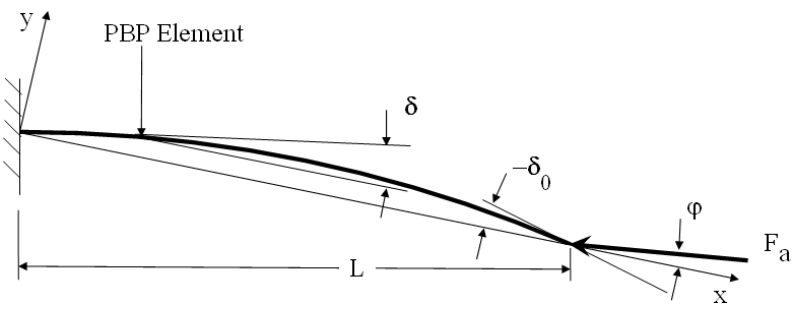

Figure 1. Terms and conventions for analysis of the PBP actuator in a cantilevered configuration.

$\left(<15^{\circ}\right)$. The normal strain in the laminate at any distance $y$ from the neutral axis through its thickness is expressed as:

$$
\epsilon=\frac{y \mathrm{~d} \delta}{\mathrm{d} s}=\frac{\sigma}{E} .
$$

For a beam element in pure bending the following holds:

$$
\sigma=\frac{M y}{I} \text {. }
$$

Combining equations (5) and (6) and inserting CLPT conventions and terminology the following can be obtained:

$$
\frac{y \mathrm{~d} \delta}{\mathrm{d} s}=\frac{M y}{D_{1} b} .
$$

The moment that is externally applied results from the compressive force, $F_{\mathrm{a}}$ :

$$
M=F_{\mathrm{a}}((x-L) \sin \varphi-y \cos \varphi) .
$$

Inserting this in equation (7) results in:

$$
\frac{\mathrm{d} \delta}{\mathrm{d} s}=\frac{F_{\mathrm{a}}((x-L) \sin \varphi-y \cos \varphi)}{D_{\mathrm{l}} b} .
$$

Differentiating equation (9) to $s$ :

$$
\frac{\mathrm{d}^{2} \delta}{\mathrm{d} s^{2}}=\frac{F_{\mathrm{a}}(\cos \delta \sin \varphi-\sin \delta \cos \varphi)}{D_{\mathrm{l}} b} .
$$

Multiplying through by integration factor $2 \mathrm{~d} \delta / \mathrm{d} s$

$$
2 \frac{\mathrm{d} \delta}{\mathrm{d} s} \frac{\mathrm{d}^{2} \delta}{\mathrm{d} s^{2}}=2 \frac{F_{\mathrm{a}}(\cos \delta \sin \varphi-\sin \delta \cos \varphi)}{D_{\mathrm{l}} b} \frac{\mathrm{d} \delta}{\mathrm{d} s} .
$$

Integrating equation (11) with respect to $s$ :

$$
\left(\frac{\mathrm{d} \delta}{\mathrm{d} s}\right)^{2}=2 \frac{F_{\mathrm{a}}(\sin \delta \sin \varphi+\cos \delta \cos \varphi)}{D_{\mathrm{l}} b}+a .
$$

At $x=L$ and $y=0$ the compressive force creates no moment, so the curvature is determined solely by the curvature induced by the piezoelectric elements: $(\mathrm{d} \delta / \mathrm{d} s)_{x=L}=\kappa$ and $\delta_{x=L}=$ $-\delta_{0}$. The integration constant, $a$, can then be calculated:

$$
a=\kappa^{2}-2 \frac{F_{\mathrm{a}}\left(\cos \delta_{0} \cos \varphi-\sin \delta_{0} \sin \varphi\right)}{D_{\mathrm{l}} b} .
$$

Substituting equation (13) in equation (12):

$$
\begin{gathered}
\left(\frac{\mathrm{d} \delta}{\mathrm{d} s}\right)^{2}=\frac{2 F_{\mathrm{a}}}{D_{1} b}\left[\left(\sin \delta+\sin \delta_{0}\right) \sin \varphi\right. \\
\left.+\left(\cos \delta-\cos \delta_{0}\right) \cos \varphi\right]+\kappa^{2}
\end{gathered}
$$




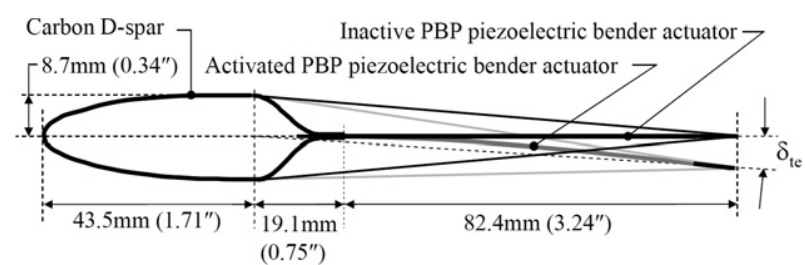

Figure 2. Change in airfoil camber due to PBP actuation.

Considering the negative root, because $\mathrm{d} \delta$ is always negative, the following follows:

$$
\begin{aligned}
\frac{\mathrm{d} \delta}{\mathrm{d} s} & =-\sqrt{\frac{2 F_{\mathrm{a}}}{D_{\mathrm{l}} b}} \\
& \times \sqrt{\left(\sin \delta+\sin \delta_{0}\right) \sin \varphi+\left(\cos \delta-\cos \delta_{0}\right) \cos \varphi+\frac{\kappa^{2} D_{1} b}{2 F_{\mathrm{a}}}} .
\end{aligned}
$$

Integrating both sides:

$$
\begin{aligned}
\int_{0}^{L} & \sqrt{\frac{2 F_{\mathrm{a}}}{D_{\mathrm{l}} b}} \mathrm{~d} s= \\
& \int_{-\delta_{0}}^{\delta_{0}} \frac{\mathrm{d} \delta}{\sqrt{\left(\sin \delta+\sin \delta_{0}\right) \sin \varphi+\left(\cos \delta-\cos \delta_{0}\right) \cos \varphi+\frac{\kappa^{2} D_{1} b}{2 F_{\mathrm{a}}}}} .
\end{aligned}
$$

Combining equation (16) with equation (4) results in a unique closed form solution for the deflection, $\delta_{0}$, for each combination of $F_{\mathrm{a}}$ and $\Lambda$ :

$$
\begin{aligned}
& L \sqrt{\frac{2 F_{\mathrm{a}}}{D_{\mathrm{l}} b}}= \\
& \quad \int_{-\delta_{0}}^{\delta_{0}} \frac{\mathrm{d} \delta}{\sqrt{\left(\sin \delta+\sin \delta_{0}\right) \sin \varphi+\left(\cos \delta-\cos \delta_{0}\right) \cos \varphi+\frac{\left(B_{\mathrm{a}} \Lambda\right)^{2} b}{2 D_{1} F_{\mathrm{a}}}}} .
\end{aligned}
$$

\section{Actuator design and integration}

\subsection{Overall design}

The objectives for this morphing wing study were to: decrease total aircraft operational empty weight, reduce power consumption, drag, part count and minimize costs. From a performance point of view, a high break frequency and a low drag were desired. These requirements drove the design of the morphing wing panels based on PBP actuators used in place of

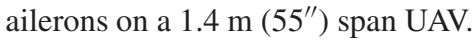

A modified D-spar formed the airfoil curvature over the first $30 \%$ of the NACA 0012 airfoil which was the section chosen for the morphing wing panels. Connected to this tapered D-beam at the $40 \%$ chord were the PBP actuators which extended to the trailing edge at the $98 \%$ chord. A highly compliant skin tube was stretched chordwise over the airfoil. The skin was made of natural rubber and made contact with the rigid part of the structure at the thickest point of the D-spar and at the trailing edge. By applying an electric field to the PBP

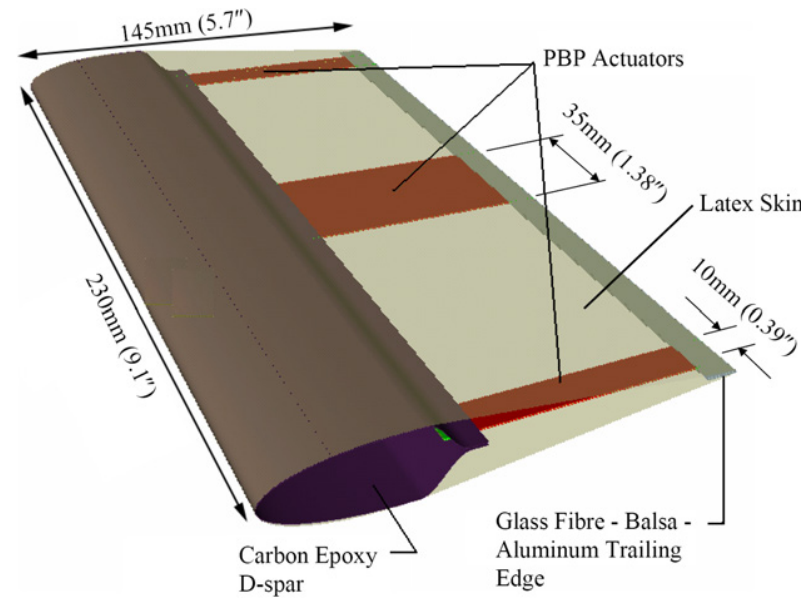

Figure 3. Design of the morphing wing panel.

(This figure is in colour only in the electronic version)

elements, the trailing edge was forced to deflect downward which induced a change in camber as well as in thickness distribution of the airfoil (see figure 2). It was this change in airfoil geometry that could alter the local aerodynamic loading of the wing and could be used to generate rolling moments.

The deformable airfoil was converted into a threedimensional wing panel design that was to be positioned at the outboard stations of a $1.4 \mathrm{~m}$ span wing. Each of the morphing panels measured $230 \mathrm{~mm}\left(9.1^{\prime \prime}\right)$ in width and $145 \mathrm{~mm}\left(5.7^{\prime \prime}\right)$ in chord. In total, $32 \%$ of the wing span could be actively deformed via the PBP actuators. To transfer all the loads from the skin to the static part of the wing, a carbon D-spar was designed. The $\mathrm{D}$-spar was intended to give rigidity to the structure in both bending and torsion. Figure 3 shows the design of the deformable part of the wing. In compliance with the requirement of low complexity, the number of parts for this wing panel amounted to only six: three actuator elements, a torque box, a trailing edge stiffener and the highly compliant skin.

In this design, the rubber skin was taut so as to apply an axial force on the PBP actuator elements. The rubber skin (with an initial length of $51 \mathrm{~mm}\left(2.0^{\prime \prime}\right)$ ) was strained $200 \%$ to span the perimeter of the airfoil, where strain was defined to be $\epsilon=(\Delta x / L), \Delta x$ being the amount of extension and $L$ being the initial length. At $200 \%$ strain the skin exerted a force per unit width of $16.91 \mathrm{gmf} \mathrm{mm}^{-1}$. This force acted over the entire span of the morphing panel $\left(b_{m}=230 \mathrm{~mm}\right)$. The trailing edge stiffener distributed this load equally over the three PBP actuators that together spanned $55 \mathrm{~mm}$. Accordingly, the total axial force applied to each actuator per unit actuator width was $70.7 \mathrm{gmf} \mathrm{mm}^{-1}$.

In the neutral position the skin applied an axial force that was aligned with the neutral line of the actuator $(\varphi=0)$. Upon actuation, the resultant of the forces generated by the upper and lower skin did not coincide with the $x$ axis anymore $(\varphi \neq 0)$. Assuming that deflections were small $\left(\sin \delta_{0} \simeq \delta_{0}, \cos \delta_{0} \simeq 1\right)$, the angle $\varphi$ was determined as follows:

$$
\varphi=\frac{1}{2}\left(\frac{L \delta_{0}+y_{\mathrm{u}}}{x_{\mathrm{u}}-L}+\frac{L \delta_{0}+y_{1}}{x_{1}-L}\right)+\delta_{0} ;
$$




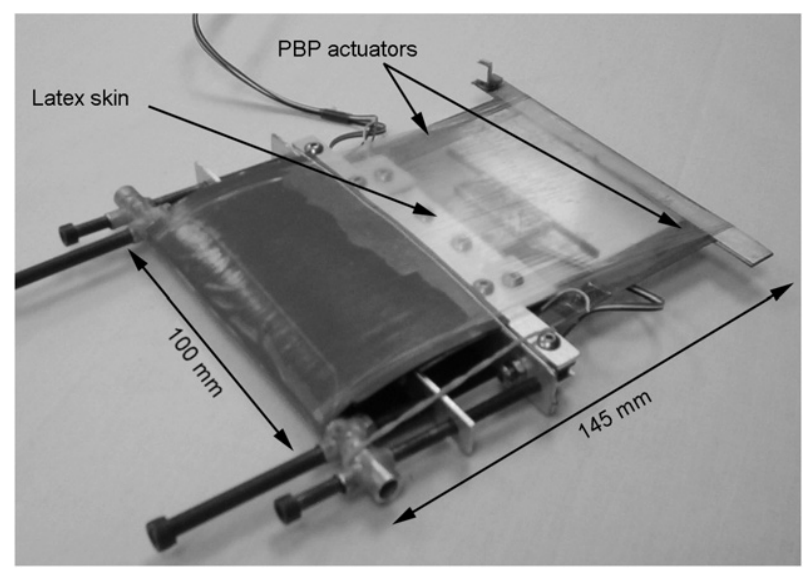

Figure 4. Test article dimensions and features.

where $\left(x_{\mathrm{u}}, y_{\mathrm{u}}\right)$ were the attachment coordinates of the upper skin and $\left(x_{1}, y_{1}\right)$ were the attachment coordinates of the lower skin.

Apart from exerting an axial force on the PBP actuators, the skin also functioned as an aerodynamic surface. Due to the relatively high tension in the skin, the out-of-plane displacement of the skin due to the pressure distribution was assumed to be small.

\subsection{PBP morphing wing test article fabrication}

For the skin, natural rubber (latex) was chosen, because it was easy to purchase, inexpensive and came in different thicknesses. The thickness, in combination with the amount of strain, determined the amount of precompression on the PBP element which was critical to precisely prescribe so that the PBP elements would not be overstressed. Experiments were carried out to find a skin which would have the right thickness to provide the desired precompressive force. A test article was fabricated which consisted of a $100 \mathrm{~mm}\left(4^{\prime \prime}\right)$ wide airfoil section, with two PBP actuator elements, each measuring $15 \mathrm{~mm}\left(0.59^{\prime \prime}\right)$ in width. The chord could be adjusted from 130 to $155 \mathrm{~mm}\left(5.2^{\prime \prime}\right.$ to $\left.6.2^{\prime \prime}\right)$ in order to change the strain in the skin, thereby enabling accurate precompression levels. Figure 4 shows the test article.

\section{Experimental testing and results}

\subsection{Quasi-static bench testing}

Quasi-static bench tests were conducted to show the feasibility of the morphing wing concept and to prove that the deflection levels could be increased substantially when precompression was applied, while maintaining good force generation capability. Figure 5 shows a side-view of the test article in a benchtop fixture. It can be seen that, by deflecting the PBP elements, the total outer airfoil shape was deformed substantially. This showed that in an unloaded situation (no aerodynamic forces present) large-scale active deformation of the wing structure could be obtained using PBP elements.

The test article was used to determine the deflections of the PBP elements, with and without skin applied. Tests were carried out by using sine wave driving signals at a frequency of $0.1 \mathrm{~Hz}$. By reflecting a laser off a $5 \mathrm{~mm}$ diameter laser mirror attached to the trailing edge of the bench test article, end rotations were measured with an accuracy of one tenth of a degree. By adjusting the chord length it was shown that at a chord length of $145 \mathrm{~mm}\left(5.8^{\prime \prime}\right)$ the deflection levels increased more than two times with respect to the skin-off configuration. Figure 6 shows that a peak-to-peak end rotation of $\theta=15.25^{\circ}$ was reached with good correlation between theory and experiment.

\subsection{Dynamic bench testing}

To determine the change in natural frequency and corner frequency due to the presence of the skin, a dynamic bench test was carried out. A frequency sweep at low voltage $\left(<100 \mathrm{~V} \mathrm{~mm}^{-1}\right.$ field strength over the piezoelectric sheets) level was used in order to find the resonance peak for both the skin-on and the skin-off configuration of the test article. End rotations were recorded and normalized with respect to the quasi-static end rotations. Figure 7 shows how the resonance peak shifted from 31 to $26 \mathrm{~Hz}$. Furthermore it can be seen that the corner frequency of the actuator shifted from 38 to $34 \mathrm{~Hz}$. Above the corner frequency, the end-rotations decreased at approximately $10 \mathrm{db} /$ decade till they became immeasurable at just under $100 \mathrm{~Hz}$.

Neglecting the mass increment due to the application of the skin, the relative passive stiffness of the wing can be
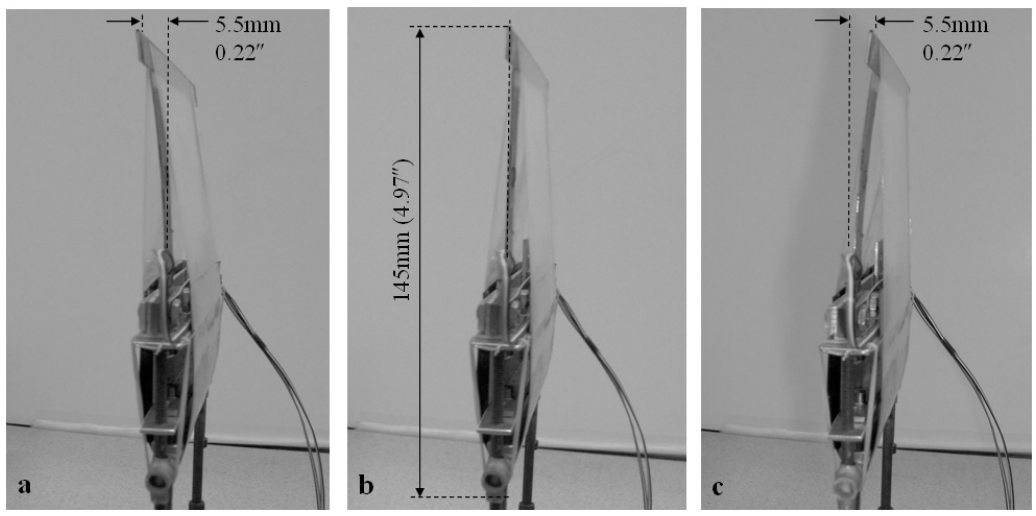

Figure 5. PBP deflections during quasi-static bench tests. 


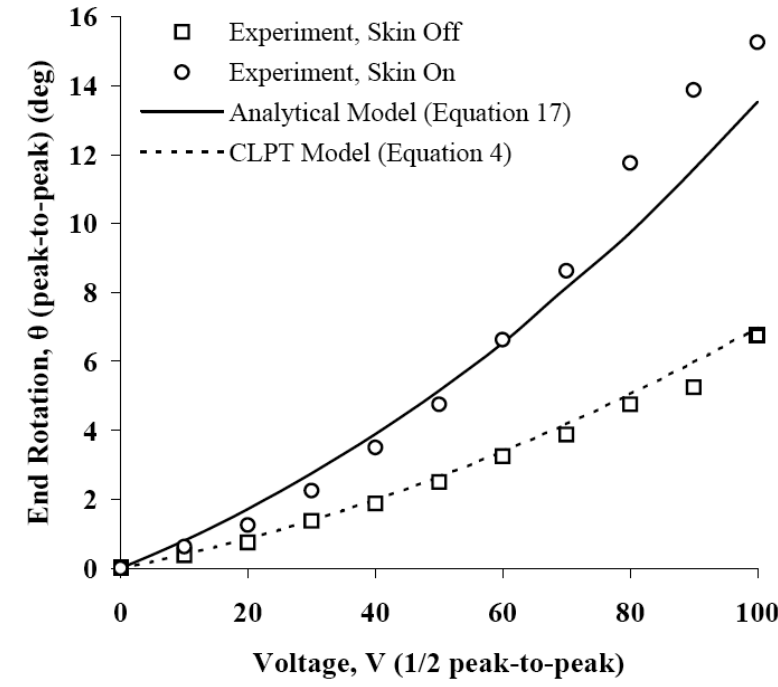

Figure 6. Quasi static end rotations as a function of voltage.

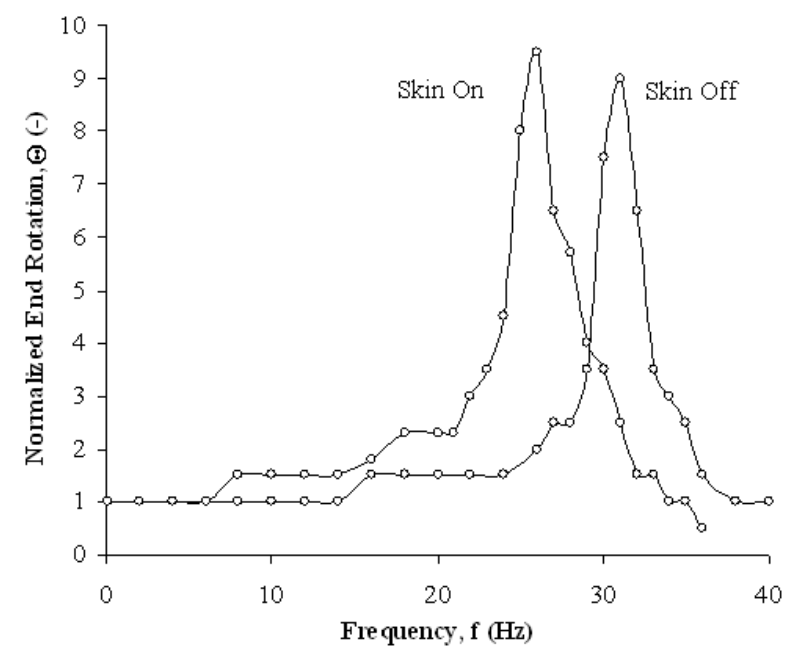

Figure 7. Normalized end rotations as a function of actuation frequency.

calculated using:

$$
\frac{K_{\text {skin on }}}{K_{\text {skin off }}}=\frac{\omega_{\text {skin on }}^{2}}{\omega_{\text {skin off }}^{2}} .
$$

Substituting the aforementioned values shows that the net stiffness in the actuator assembly was reduced to $70 \%$ of the original stiffness. From the dynamic tests, it could be concluded that the precompression induced by the skin could be still further increased in order to decrease the effective stiffness even further. A result of even higher precompression loads would have been higher curvatures. However, higher curvatures would have increased the chance of tensile failure of the convex piezoceramic elements. The maximum axial load would have been the perfect column buckling load at which the natural frequency of the system would, in theory, approach zero. Because the elements needed to be flight-hardened, it was decided that a twofold amplification level would work well simply to demonstrate the concept and system.

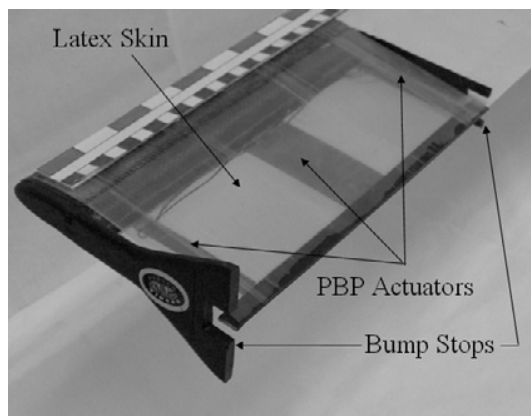

Figure 8. Assembled morphing wing panel.

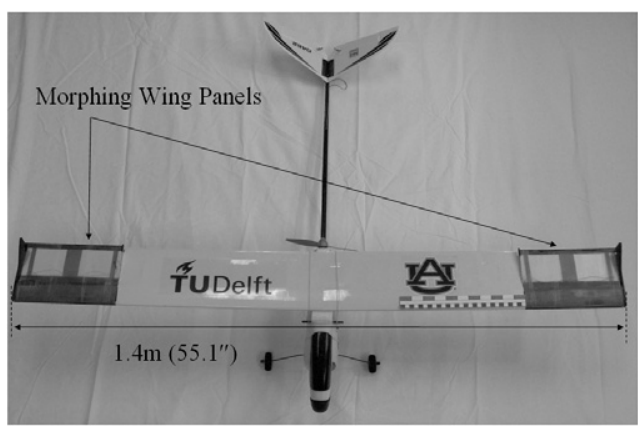

Figure 9. PBP wing mounted on the UAV (top view).

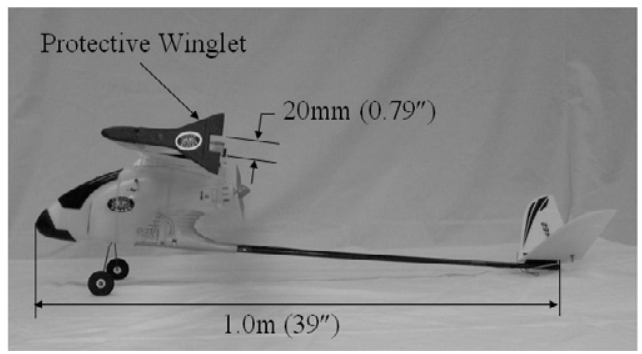

Figure 10. PBP wing mounted on the UAV (side view).

\subsection{Flight testing}

To prove the PBP actuated morphing panels in flight, a $1.4 \mathrm{~m}$ $\left(55^{\prime \prime}\right)$ span subscale UAV was equipped with a new wing employing morphing panels at the outboard stations. The wing was straight (no taper or sweep) outboard PBP panels employed NACA 0012 airfoil sections. The wing possessed a dihedral angle of $2^{\circ}$ with a chord of $145 \mathrm{~mm}\left(5.7^{\prime \prime}\right)$. The morphing panels were positioned between the $68 \%$ and the $99 \%$ of the semi-span of the wing. Figure 8 shows the assembled left hand morphing panel.

The static part of the wing was made out of Balsa wood, using conventional subscale UAV fabrication techniques. To prevent the PBP elements from over-rotating during flight, bump stops were implemented at both edges of each morphing part of the wing. The bump stops were integrated into winglets which were designed to protect the PBP ailerons from handling and ground-contact loads. The maximum allowed vertical tip travel of the trailing edge was restricted to $20 \mathrm{~mm}\left(0.39^{\prime \prime}\right)$ peakto-peak. Figures 9 and10 depict the entire aircraft, including the wing with morphing panels at the outboard stations. 


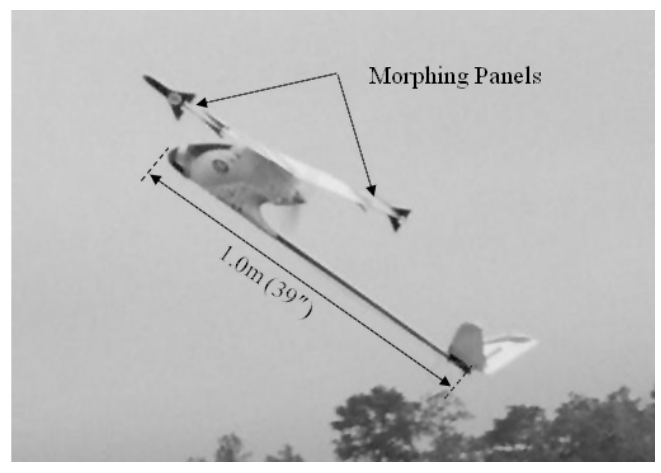

Figure 11. Morphing wing UAV flight test.

Table 1. Comparison of the electromechanical servoactuator and PBP actuator.

\begin{tabular}{lll}
\hline & Conventional servoactuator & PBP actuator \\
\hline Max. power & $24 \mathrm{~W}$ & $100 \mathrm{~mW}$ \\
Max. current & $5 \mathrm{~A}$ & $1.4 \mathrm{~mA}$ \\
Mass increment & $59 \mathrm{~g}$ & $3 \mathrm{~g}$ \\
Slop & $1.6^{\circ}$ & $0.02^{\circ}$ \\
Corner frequency & $3 \mathrm{~Hz}$ & $34 \mathrm{~Hz}$ \\
Part count & 56 & 6 \\
\hline
\end{tabular}

Successful flight testing was carried out on 29 April 2005 in Auburn, Alabama under light and variable $5 \mathrm{kt}$ winds, $15^{\circ} \mathrm{C}$ $\left(59^{\circ} \mathrm{F}\right)$ and 7 statute miles of visibility. Flight test showed excellent roll control. Figure 11 shows the aircraft just after take-off. With respect to the baseline aircraft, the new PBP equipped aircraft had roughly $38 \%$ more roll control authority. Furthermore, control derivatives (e.g. the rate of change in rolling moment with respect to trailing edge deflection, $C_{l_{\delta} \text { te }}$ ) increased by a factor of 3.7 [30].

\subsection{Integration characteristics and comparison}

Significant benefits were obtained by switching from a conventional aileron actuated wing to a PBP controlled morphing wing. The PBP equipped wings did not employ any linkages, gears, or heavy servomotors, pushrods, control horns or linkages and were therefore significantly lighter. Since PBP actuators operated under a high voltage but very low current, power consumption and the weight of the control lines was decreased substantially [27]. This in turn led to a reduction in battery capacity and consequently battery weight. Unlike conventional servoactuators, the PBP actuators were solid state, so part count, slop and deadband were one to two orders of magnitude lower [13]. Table 1 shows how PBP actuators compare to conventional electromechanical servoactuators.

In addition to the aforementioned benefits, the actuator very synergistically formed an integral part of the wing structure. Therefore, the weight of the actuator was not added to the structure, but could already be counted as part of the structural weight. Each panel weighed in total (including wiring) only $43 \mathrm{~g}$, which compares to a specific weight of $186 \mathrm{gmf} \mathrm{m}^{-1}$ span $[28,29]$. This was only a fraction higher than the specific weight of the Balsa static structure which amounted to $180 \mathrm{gmf} \mathrm{m}^{-1}$ span. Consequently, the weight increment due to the actuators for this wing amounted to only $3 \mathrm{~g}$, which is substantially less than the $59 \mathrm{~g}$ a conventional actuator would add to the aircraft's weight. The complexity of the structure could be greatly reduced by using the skin as an aerodynamic surface and at the same time as precompression tool. Moreover, using a PBP actuated morphing wing increased the actuation frequency by an order of magnitude over conventional actuators, with excellent control authority.

\section{Conclusions}

It can be concluded that post-buckled precompressed (PBP) piezoelectric driven morphing UAV wings have significant benefits over conventionally driven wings. A deflection model employing nonlinear structural relations was shown to predict the behavior of axially compressed PBP elements very well. These elements were designed to be part of a morphing wing structure to take the place of ailerons on a subscale UAV. The PBP elements lead to a weight impact on the total aircraft operating empty weight of only $3 \mathrm{~g}$, as compared to conventional servoactuators which induce a $59 \mathrm{~g}$ weight penalty. Extensive testing demonstrated that, by using an elastomeric skin to axially precompress the bender elements, deflections could be increased by more than a factor of two. It was shown that trailing edge angular deflections in excess of $15^{\circ}$ peak-to-peak could be generated at speeds up to $34 \mathrm{~Hz}$ for under $100 \mathrm{~mW}$ of total power consumption. It was shown during flight that wing morphing could produce $38 \%$ more roll control and 3.7 times greater control derivatives than conventional approaches. Because PBP actuators are solid state and do not employ any linkages, pushrods or gears, they operate very efficiently This efficiency leads to a $99.6 \%$ decrease in power consumption, $87 \%$ reduction in flight control system-related weight, an order of magnitude increase in control actuation bandwidth, and an order of magnitude fewer parts than conventional electromechanical servoactuators.

\section{Acknowledgments}

The authors would like to thank the outstanding contributions of the many students and colleagues who helped with this study, including Mr Shannon Wheatley, Mr Christoph Burger, Mr Lars Krakers and Professor Michel van Tooren. This study was sponsored by the Department of Aerospace Engineering of Auburn University and the Faculty of Aerospace Engineering of the Delft University of Technology, The Netherlands.

\section{References}

[1] Barrett R 1990 Intelligent rotor blade and structures development using directionally attached piezoelectric crystals MS Thesis University of Maryland

[2] Barrett R, Gross R S and Brozoski F 1996 Missile flight control using active flexspar actuators Smart Mater. Struct. 5 121-8

[3] Barrett R, Gross R S and Brozoski F 1995 Design and testing of subsonic all-moving smart flight control surfaces Proc. 36th AIAA Conf. on Structures, Structural Dynamics and Control (New Orleans, LA, April 1995) (Washington, DC: American Institute of Aeronautics and Astronautics) AIAA paper no. 95-1081 
[4] Ehlers S and Weisshaar T 1990 Static aeroelastic behavior of an adaptive laminated piezoelectric composite wing Proc. 31st AIAA/ASME/ASCE/AHS/ASC Structures, Structural Dynamics and Materials Conf. (Long Beach, CA, April 1990) (Washington, DC: American Institute of Aeronautics and Astronautics) AIAA paper no. 1990-1078

[5] Ehlers S and Weisshaar T 1992 Effect of material properties on static aeroelastic control Proc. 33rd AIAA/ASME/ASCE/AHS/ASC Structures, Structural Dynamics and Materials Conf. (Dallas, TX, April 1992) (Washington, DC: American Institute of Aeronautics and Astronautics) AIAA paper no. 92-2526

[6] Barrett R 1992 Active plate and wing research using EDAP elements Smart Mater. Struct. 1 214-26

[7] Barrett R 1995 Method and apparatus for structural actuation and sensing in a desired direction US Patent 5,440,193 (Aug. 1995)

[8] Barrett R and Stutts J 1997 Design and testing of a 1/12th scale solid state adaptive rotor Smart Mater. Struct. 6 491-7

[9] Barrett R 2004 Adaptive aerostructures - the first decade of flight on uninhabited aerospace systems Proc. Society of Photo-Optical Instrumentation Engineers (SPIE) Annual Int Symp. on Smart Structures and Materials; Proc. SPIE 5388 190-201

[10] Barrett R, Burger C and Melian J 2001 Recent advances in uninhabited aerial vehicle (UAV) flight control with adaptive aerostructures Proc. 4th European Demonstrators Conf. (Edinburgh, Scotland, Dec. 2001) (Bristol: Institute of Physics Publishing) pp 1-11

[11] Garcia H, Abdulrahim M and Lind R 2003 Roll control for a micro air vehicle using active wing morphing Proc. AIAA Guidance, Navigation, and Control Conf. and Exhibit (Austin, TX, Aug. 2003) (Washington, DC: American Institute of Aeronautics and Astronautics) AIAA paper no. 2003-5347

[12] Barrett R M and Tiso P 2005 PBP Adaptive actuator device and embodiments International Patent Application PCT/NL2005/000054 Delft University of Technology (18 Feb. 2005)

[13] Barrett R, McMurtry R, Vos R, Tiso P and De Breuker R 2005 Post-buckled precompressed (PBP) elements: a new class of flight control actuators enhancing high speed autonomous VTOL MAVs Society of Photo-Optical Instrumentation Engineers (SPIE) Annual Int. Symp. on Smart Structures and Materials; Proc. SPIE 5762 111-22

[14] Barrett R, Vos R, Tiso P and De Breuker R 2005 Post-buckled precompressed (PBP) actuators: enhancing VTOL autonomous high speed MAVs Proc. 46th AIAA/ASME/ASCE/AHS/ASC Structures, Structural Dynamics and Materials Conf. (Austin, TX, April 2005) (Washington, DC: American Institute of Aeronautics and Astronautics) AIAA paper no. 2005-2113

[15] Moskalik A J and Brei D 1997 Deflection-voltage model and experimental results for polymeric piezoelectric c-block actuators AIAA J. 35 1556-8
[16] Ervin J D and Brei D 1998 Recurve piezoelectric-strainamplifying actuator architecture IEEE/ASME Trans. Mechatron. 3 293-301

[17] Niezrecki C, Brei D, Balakrishnan S and Moskalik A 2001 Piezoelectric actuation: state of the art Shock Vib. Digest 33 269-80

[18] Devoe D L and Pisano A P 1997 Modeling and optimal design of piezoelectric cantilever micro-actuators J. Microelectromech. Syst. 6 266-70

[19] Kim S G and Koo M K 2000 Design of a micro-actuator array against the coupled nature of microelectromechanical systems (MEMS) processes Ann. CIRP 49101

[20] Steyn J L, Li H Q, Roberts D C, Turner K T, Yaglioglu O, $\mathrm{Su}$ Y H, Schmidt M A, Spearing S M, Hagood N W and Micak R 2002 Hydraulic amplification devices for microscale actuation Solid-State Sensor, Actuator and Microsystems Workshop (Hilton Head Island, SC, June) pp 50-3

[21] Lesieutre G A and Davis C L 1997 Can a coupling coefficient of a piezoelectric actuator be higher than those of its active material? J. Intell. Mater. Syst. Struct. 8 859-67

[22] Lesieutre G and Davis C 2001 Transfer having a coupling coefficient higher than its active material US Patent 6,236,143 (May 2001)

[23] Benjeddou A 2000 Advances in piezoelectric finite element modeling of adaptive structural elements: a survey Comput. Struct. 76 347-63

[24] Giannopoulos G, Santafe Iribarren F and Vantomme J 2006 Thermal-electrical-mechanical coupled FE buckling analysis of smart plates using discrete layer kinematics Society of Photo-Optical Instrumentation Engineers (SPIE) Annual Int. Symp. on Smart Structures and Materials; Proc. SPIE $6166218-28$

[25] De Breuker R, Tiso P, Vos R and Barrett R 2006 Nonlinear semianalytical modeling of postbuckled precompressed (PBP) piezoelectric actuators for UAV flight control Proc. 47th AIAA/ASME/ASCE/AHS/ASC Structures, Structural Dynamics and Materials Conf. (Newport, RI, April 2006) (Washington, DC: American Institute of Aeronautics and Astronautics) AIAA paper no. 2006-1795

[26] Jones R M 1975 Mechanics of Composite Materials (New York: Hemisphere)

[27] Bramlette R and Leurck R 2005 A method for control surface deflection utilizing piezoceramic bimorph actuators Proc. 44th AIAA Aerospace Sciences Mtg and Exhibit (Reno, NV, Jan. 2006) (Washington, DC: American Institute of Aeronautics and Astronautics) AIAA paper no. 2006-146

[28] Vos R, De Breuker R, Barrett R and Tiso P 2006 Morphing wing flight control via post-buckled precompressed piezoelectric actuators J. Aircraft to be published

[29] Vos R, Barrett R, Krakers L and Van Tooren M 2006 Post-buckled precompressed (PBP) piezoelectric actuators for UAV flight control Society of Photo-Optical Instrumentation Engineers (SPIE) Annual Int. Symp. on Smart Structures and Materials; Proc. SPIE 6173 121-32

[30] Roskam J 1990 Airplane Design, Part 6: Preliminary Calculation of Aerodynamic, Thrust and Power Characteristics (Lawrence, KS: DARcorp Publishing) 